\title{
A loucura como fenômeno transindividual: sobre a folie-à-deux, segundo Lasègue e Falret
}

\section{Mário Eduardo Costa Pereira}

O campo dos fenômenos psicóticos, tal como costumamos concebê-los, parece constituir a própria expressão do isolamento subjetivo em seu estado mais extremo, a ponto de o indivíduo romper com a matriz simbólica que o ligava à realidade socialmente compartilhada e, por extensão, aos demais humanos. As construções delirantes, os neologismos, os estados alucinatórios, as alterações das vivências do próprio eu e da realidade testemunham de uma ruptura com as formas socializadas de apreensão e significação do mundo, remetendo o sujeito à desestruturação psíquica, ao isolamento e à necessidade de edificar por si mesmo uma nova base de sentido para sua existência. Mas se a psicose é antes de tudo a expressão mais radical da ruptura do contato com o universo humano simbolicamente estruturado, o que dizer então quando uma mesma concepção delirante é compartilhada por dois parceiros que passam a estabelecer uma referência de significações válida apenas para eles próprios? Essas são as situações psicopatológicas das quais Charles Lasègue e Jules Falret procuraram dar conta em sua célebre monografia "La folie à deux", de 1877.

Em 1852, o grande clínico francês Charles Lasègue (18161883) descreve o délire de persécution, quadro paranóico de evolução progressiva, que inicia com fenômenos interpretativos os quais vão se desdobrando em uma construção alucinatória 


\section{$\begin{array}{lllllll}R & E & V & I & S & T & A\end{array}$

fundamentalmente auditiva. No desenvolvimento de suas pesquisas sobre essa psicopatologia, Lasègue publica, em colaboração com Jules Falret (1824-1902), o estudo "La folie à deux ou folie comuniquée".

Nesse texto, do qual a presente edição da Revista Latinoamericana de Psicopatologia Fundamental traduz a parte inicial, os autores propõem o exame de situações mórbidas na quais aqueles que convivem com o alienado terminam por se deixar influenciar por eles, aderindo a seus sistemas delirantes: “O problema compreende então dois termos, entre os quais trata-se de estabelecer uma equação: de um lado, o doente ativo, de outro, o indivíduo receptivo que sofre sua influência sob formas e graus diversos”. Tal propensão mórbida à adesão à loucura de um sujeito delirante depende, segundo o texto, de que o segundo parceiro tenha uma "inteligência fraca, mais disposta à docilidade passiva do que à emancipação”; além disso, é necessário "que ele viva em relação constante com o doente”; por fim, é preciso que ele esteja engajado pelo estímulo de um interesse pessoal: "Não se sucumbe à fraude a não ser pela sedução de um lucro, qualquer que seja. Não se cede à pressão da loucura a não ser que ela o faça entrever a realização de um sonho acalentado”. Dessa forma, Lasègue e Falret tendem a considerar apenas o delirante primitivo legitimamente psicótico, enquanto o segundo é visto como um indivíduo frágil, o qual, devido a uma situação de proximidade, intimidade e isolamento, acaba por se deixar fascinar e envolver pelo sistema delirante do primeiro.

Eugen Bleuler, já no século XX, denominou esse tipo de situação de "loucura induzida”, considerando-a um evento que ocorre sobretudo em pacientes paranóides ou, mais raramente, hipomaníacos, que conseguem convencer alguém de sua convivência da realidade de seus delírios. Progressivamente, ambos passam a compartilhar um sistema delirante e tal situação tem por efeito reassegurar os parceiros quanto à legitimidade de suas idéias e a encorajar-lhes o desenvolvimento cada vez mais sistemático de suas concepções alienadas. A visão de Bleuler sobre este fenômeno destaca a dimensão de “indução” à loucura que um indivíduo exerce sobre o outro. Em seu Tratado de Psiquiatria, Bleuler (1967, p. 588-9), destaca o fato de que “o indutor primariamente enfermo é de caráter enérgico”. Por sua vez, o segundo parceiro apresenta particular susceptibilidade à influência das idéias do primeiro, sendo que ambos participam ativamente para a elaboração do sistema delirante. Considera, por fim, tal como Lasègue e Falret, que não é freqüente a instalação de "uma loucura propriamente dita baseada na indução do ser patológico de um enfermo mental sobre um sujeito são”, embora a convivência prolongada e em condições de isolamento com tais indivíduos tendam a produzir sobre o parceiro traços leves dos fenômenos psicóticos, tais como desconfiança e idéias sobrevalorizadas. 
A folie à deux constitui uma condição psicopatológica relativamente rara, embora praticamente não existam estudos de prevalência ou de incidência, sendo que a literatura sobre o tema baseia-se quase exclusivamente em relatos de caso (cf. Kaplan \& Sadock, 1995, p. 1044).

Em geral, os indivíduos envolvidos têm relações pessoais muito estreitas, sendo comum que convivam por longo tempo em condições de isolamento social. A folie à deux tende a implicar relações de irmã-irmã, marido-esposa, mãe-filho, embora outros tipos de relacionamento também sejam observados.

A forma clínica mais comum é a chamada folie imposée, na qual um indivíduo apresentando o quadro delirante acaba exercendo forte influência sobre uma pessoa próxima, psicologicamente vulnerável, a qual termina por aderir ao sistema psicótico do primeiro. Tipicamente, o segundo sujeito afetado é mais tímido, menos inteligente, mais passivo e com menor auto-estima que o primeiro. Fatores como baixa inteligência, idade avançada, a presença de doenças cérebrovasculares, abuso de álcool e um histórico de quadros psicóticos na família estão relacionados a uma maior susceptibilidade à influência delirante. Quando ocorre a separação dos dois parceiros, o segundo parceiro tende a abandonar sua adesão inicial ao sistema delirante do primeiro (ibid.).

Do ponto de vista psicopatológico, o segundo parceiro pode apresentar ou não um histórico de fenômenos psicóticos prévios à instalação da folie à deux.

Uma outra forma de apresentação clínica desse transtorno mental é denominada folie simultanée, na qual o sistema delirante instala-se simultaneamente no dois parceiros.

O estado de loucura compartilhada pode envolver mais do que dois indivíduos, havendo descrições de folie à trois, à quatre etc. São igualmente descritos fenômenos psicóticos, geralmente delirantes, compartilhados por uma família (folie en famille).

Nos principais sistemas diagnósticos contemporâneos, a folie à deux é nomeada como "transtorno delirante induzido" na CID-10 e como "transtorno psicótico compartilhado”, no DSM-IV. Ambos tendem a considerar que apenas o primeiro indivíduo sofre de transtorno psicótico genuíno, enquanto o segundo apresenta uma adesão ao sistema delirante de natureza basicamente sugestiva, facilitada por sua fragilidade e isolamento, a qual tende a desaparecer com a separação dos parceiros. O DSM-IV estabelece que o diagnóstico só pode ser realizado se o segundo parceiro não apresentar histórico de transtornos psicóticos prévios ao desencadeamento da folie à deux. Além disso, esse Manual levanta uma interessante questão psicopatológica ao sustentar que um indivíduo não pode ser diagnosticado como delirante, se a crença em questão é “comumente aceita por outros membros de sua cultura ou subcultura”. Sob essa perspectiva, coloca- 
$\begin{array}{lllllll}R & E & V & I & S & T & A\end{array}$

LATINOAMERICANA

DE PSICOPATO LOGIA

F U N D A M E N TA L

ano IX, n. 4, dez/2006

se o problema da linha de demarcação entre o que seria uma folie à x participantes e uma crença infundada, mas socialmente compartilhada.

O tema da loucura compartilhada por grandes grupos vem sendo estudado no campo psiquiátrico desde a virada do século XX, em particular no contexto brasileiro, em que Raimundo Nina-Rodrigues (1939) investigou as chamadas “coletividades anormais”. Baseado na idéias de Lasègue e de Falret sobre a folie à deux e nos trabalhos de Gustave Le Bon e de Scipio Sighele sobre a psicologia coletiva, Nina-Rodrigues dedicou-se a elucidar os mecanismos de contágio mental e da influência da loucura no funcionamento das multidões (sobre esse tema, remetemos ao artigo "Nina-Rodrigues e a loucura epidêmica de Canudos", de autoria de Ana Maria Raimundo Oda, publicado na Revista Latinoamericana de Psicopatologia Fundamental, em 2000, bem como ao próprio artigo de NinaRodrigues, intitulado “A loucura epidêmica de Canudos: Antônio Conselheiro e os jagunços”, também publicado nesse mesmo número da Revista).

Em 1933, Jacques Lacan publica na revista surrealista francesa Le Minautore um comentário que se tornaria clássico sobre o tema da folie à deux: “O crime das irmãs Papin”. Tratava-se do crime cometido em Mans por duas domésticas contra a patroa e sua filha. Lacan viu nesse ato, de uma intensa brutalidade, uma mistura de delírio a dois, de homossexualidade latente, mas antes de tudo o surgimento de uma realidade inconsciente que escapava às próprias protagonistas (cf. Roudinesco, 1986). No texto, diz Lacan (1933), “Os delírios a dois estão entre as formas mais antigamente reconhecidas como psicoses. As observações mostram que estes se produzem entre parentes próximos, pai e filho, mãe e filha, irmãos ou irmãs. Digamos que seu mecanismo emana, em certos casos, da sugestão contingente exercida por um sujeito delirante ativo, sobre um sujeito débil passivo” (p. 9). E conclui sua análise vendo nesse caso criminoso a expressão de uma paixão narcísica a qual envolve as duas parceiras em uma luta entre se manterem confundidas, na busca de uma unidade ideal, e uma tentativa desesperada de separação dessa simbiose fusional pela via do assassinato: “O mal de serem duas, do qual sofrem essas doentes, não as libera quase nada do mal de Narciso... Verdadeiras almas siamesas, elas formam um mundo encerrado para sempre”. Desse drama Jean Genet tirou a peça, “Les Bonnes” e Claude Chabrol um filme: "La Cérémonie".

\section{Referências}

Bleuler, E. Tratado de psiquiatría. 2. ed. espanhola. Madrid: Espasa-Calpe, 1967.

Garrabé, J. Histoire de la schizophénie. Paris: Seghers, 1992. 
Kaplan, H. \& SAdock, B. Comprehensive Textbook of Psychiatry - VI. 6. ed. Baltimore: Willians \& Wilkins, 1995. 2 vols.

Lacan, J. Motifs du crime paranoïaque: le crime des soeurs Papin. Le Minautore, p. 312, 1933.

NinA-Rodrigues, R. A loucura epidêmica de Canudos: Antônio Conselheiro e os jagunços. Revista Latinoamericana de Psicopatologia Fundamental, ano III, n. 2, p. 145157, jun./2000.

As coletividades anormais. Rio de Janeiro: Civilização Brasileira, 1939.

OdA, A.M.G.R. Nina Rodrigues e a loucura epidêmica de Canudos. Revista Latinoamericana de Psicopatologia Fundamntal, ano III, n. 2, p. 139-144, jun./2000.

Postel, J. \& Quetel, C. (org.). Nouvelle histoire de la psychiatrie. Toulouse: Privat, 1983.

Roudinesco, E. La bataille de cent ans: l'histoire de la psychanalyse en France. Paris: Seuil, 1986. 2 vols.

Jacques Lacan: esboço de uma vida, história de um sistema de pensamento. São Paulo: Companhia das Letras, 1994.

Roudinesco, E. \& Plon, M. Dicionário de psicanálise. Rio de Janeiro: Jorge Zahar, 1998. 